\title{
A Study of Resinous Sealants for Porous Metal Castings
}

\author{
By Vernon C. F. Holm
}

\begin{abstract}
The repair of porous castings by sealing with liquid synthetic resins was investigated. The sealing efficiencies of fourteen resins were determined on porous bushings of aluminum, a copper-silicon alloy, and a red brass, impregnated by the vacuum-pressure method. Tests were made to determine the durability of the two most promising sealants by exposing specimens sealed with these resins to hot motor oil, high octane gasoline, boiling water elevated temperatures, high pressures, and thermal shock. The results suggest that this procedure for rendering porous castings pressure tight may be permissible in emergencies but that, in general, the foundryman should exert every effort to produce non-porous castings instead of trying to remedy porosity.
\end{abstract}

\section{Introduction}

The production of castings capable of retaining liquids or gases under pressure is a foundry problem that frequently entails considerable difficulties. Porous castings may result from (1) the use of a metal that has an inherent tendency towards microporosity, (2) incorrect foundry techniques, or (3) design requirements that do not provide for adequate feeding during solidification, etc. In any case internal cavities exposed during machining may provide passageways for leakage when the castings are placed in service.

Some alloys which have rather wide solidification ranges, such as certain magnesium alloys, are quite susceptible to microshrinkage. Castings of magnesium alloys, used as containers for fluids under slight pressure, therefore are frequently treated with sealants to prevent leakage. Such treatments have been satisfactory in light-metal castings for low pressure service, but the problem of eliminating porosity in castings of other metals that have to operate under more severe conditions of temperature and pressure, is more difficult.

During the recent war period when a high rate of production of vital war materials was essential, the output of pressure-tight bronze castings of certain hydraulic marine fittings and other castings was seriously hampered because of porosity rejections. In instances where the mechanical strength of the fittings was ample, in spite of the porosity, it was suggested that leaky castings could be salvaged through the use of suitable sealants as in the case of the lighter alloys. Although con-

\section{Contents}

I. Introduction $\quad \begin{array}{r}\text { Page } \\ 177\end{array}$

II. Materials and apparatus _..._. 178

III. Results of impregnation tests _._._. 179

IV. Durability tests on sealed specimens_____. 180

1. Exposure to liquids _...... 180

2. Effect of elevated temperatures_._._._. 180

3. Effect of testing at pressures in excess of $600 \mathrm{lb} / \mathrm{in}^{2}{ }^{2} \ldots \ldots \ldots 1$

4. Effect of thermal shock and aging _.... 181

V. Discussion of results and conclusions__._._._. 181

VI. References _. . _ _ 182 
siderable work was done in this connection, very little information has been published on the subject. Some of the materials that have been tried are linseed oil $[1,2]^{1}$, shellac [2], sodium silicate solutions $[2,3]$, and various types of synthetic resins $[2,3,4,5]$. In the case of castings of iron and steel, salt solutions [2, 6] have been used for accelerating the formation of rust-like corrosion products for "plugging" voids. Corse [7] reported that alcoholic solutions of phenol-formaldehyde resin were used as sealants for aluminum crankcases during World War I and that H. W. Gillett used this resin as early as 1912 for sealing aluminum intake manifolds for automobile engines. In the case of magnesium castings, tung oil is reported [8] to be a very satisfactory sealant, but during World War II its use for this application was prohibited by the War Production Board, and consequently other sealants had to be developed. Satisfactory results were obtained on magnesium castings with mixtures of styrene with either a heavy bodied linseed oil [9] or with certain synthetic resins $[10,11]$.

1 Figures in brackets indicate literature references at the end of this paper.
A satisfactory sealant should have low viscosity and good wetting properties so that it can penetrate readily into small voids. It also should be reasonably stable during storage in the liquid state. In curing it should form a resilient, adherent solid unaffected by moderately high temperatures and reasonably inert when exposed to hot oil, gasoline, water, and other common solvents.

Of the materials mentioned some are satisfactory as sealants in certain applications, but none of them can be regarded as a universal sealant. Because of the many recent developments in the field of plastics, it was considered desirable to investigate the effectiveness and durability as sealants of a number of available liquid synthetic resins. The present investigation was limited to this class of materials. Experiments were made to establish the sealing efficiency of several different resins and durability tests were conducted on specimens treated with the most efficient sealants.

\section{Materials and Apparatus}

The porous specimens that were used in this investigation were bushings 2 inches in outside diameter and 2 inches long, with a wall thickness of one-eighth inch. Some were cast to size and machined on the ends only. Others were cast oversize and machined inside and outside to dimensions. The materials were commercial aluminum, an alloy of copper and $3 \frac{1}{2}$ percent silicon, and red brass ( 85 percent copper and 5 percent each of lead, tin, and zinc). Some of the specimens had been prepared previously for another investigation; others were cast especially for this work with the melting and casting conditions controlled to favor the development of the desired amount of porosity. For the aluminum specimens this involved heating the metal to about $1,600^{\circ} \mathrm{F}\left(250^{\circ} \mathrm{F}\right.$ above the normal maximum heating temperature) which tends to develop a coarse structure and also favors gas absorption. In casting the copper alloy specimens, some of the mold surfaces were moistened with kerosene to insure the development of porous castings.

The degree of porosity in each specimen was determined by a hydrostatic pressure test. Some specimens showed considerable leakage at pressures as low as $25 \mathrm{lb} / \mathrm{in} .^{2}$ and water was emitted as a steady spray when the pressure was increased to $100 \mathrm{lb} / \mathrm{in}^{2}$. Others showed only slight signs of leakage at $600 \mathrm{lb} / \mathrm{in}^{2}$. Specimens that could withstand a pressure of $600 \mathrm{lb} / \mathrm{in}^{2}$ for 5 minutes without leaking were considered sound, and this criterion was adopted as a basis for judging the success of the sealing treatments.

Examination of sections of porous specimens showed that most of the porosity was due to microshrinkage and consisted of cavities along the grain boundaries. This is illustrated by the micrograph of a polished section of a specimen of coppersilicon alloy, shown in figure 1. The maximum width of cavity observed in any specimen was about 0.002 inch, but most of the cavities were much smaller.

The impregnating chamber shown in figure 2 was constructed for impregnation of the specimens by the vacuum-pressure method. The chamber consisted of a 12-inch length of 8-inch pipe, closed 


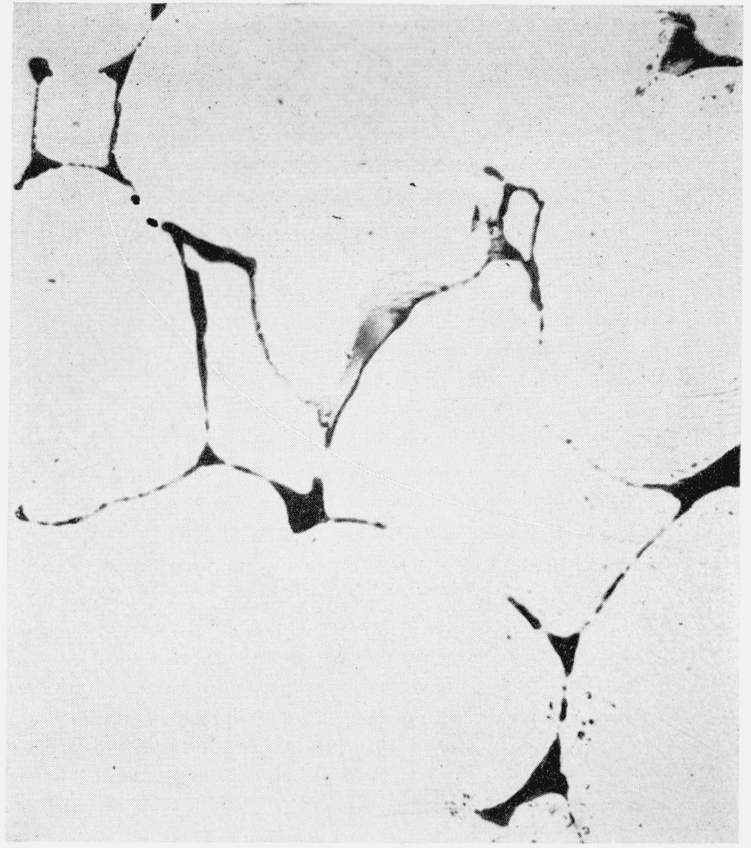

Figure 1.- Micrograph of a section of a copper-silicon alloy casting showing microporosity; unetched; $\times 500$.

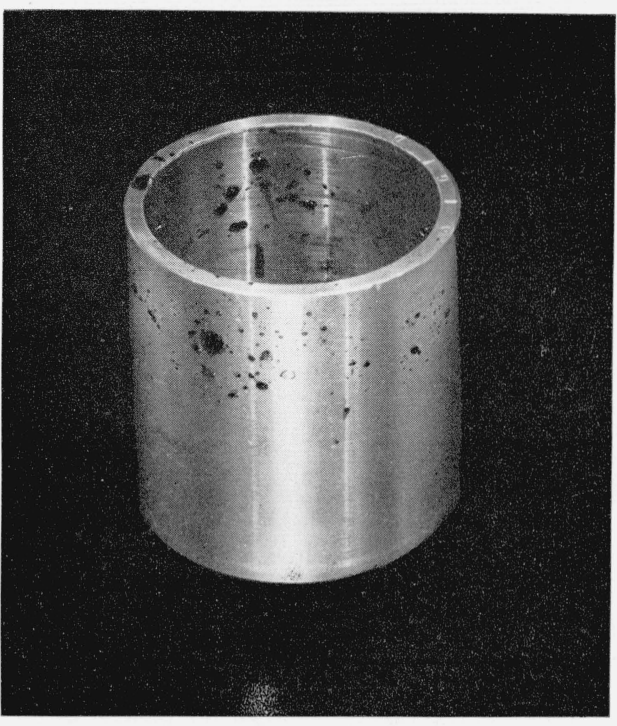

Figure 3.-Porous aluminum casting showing the exudation of resin that occurred during curing.

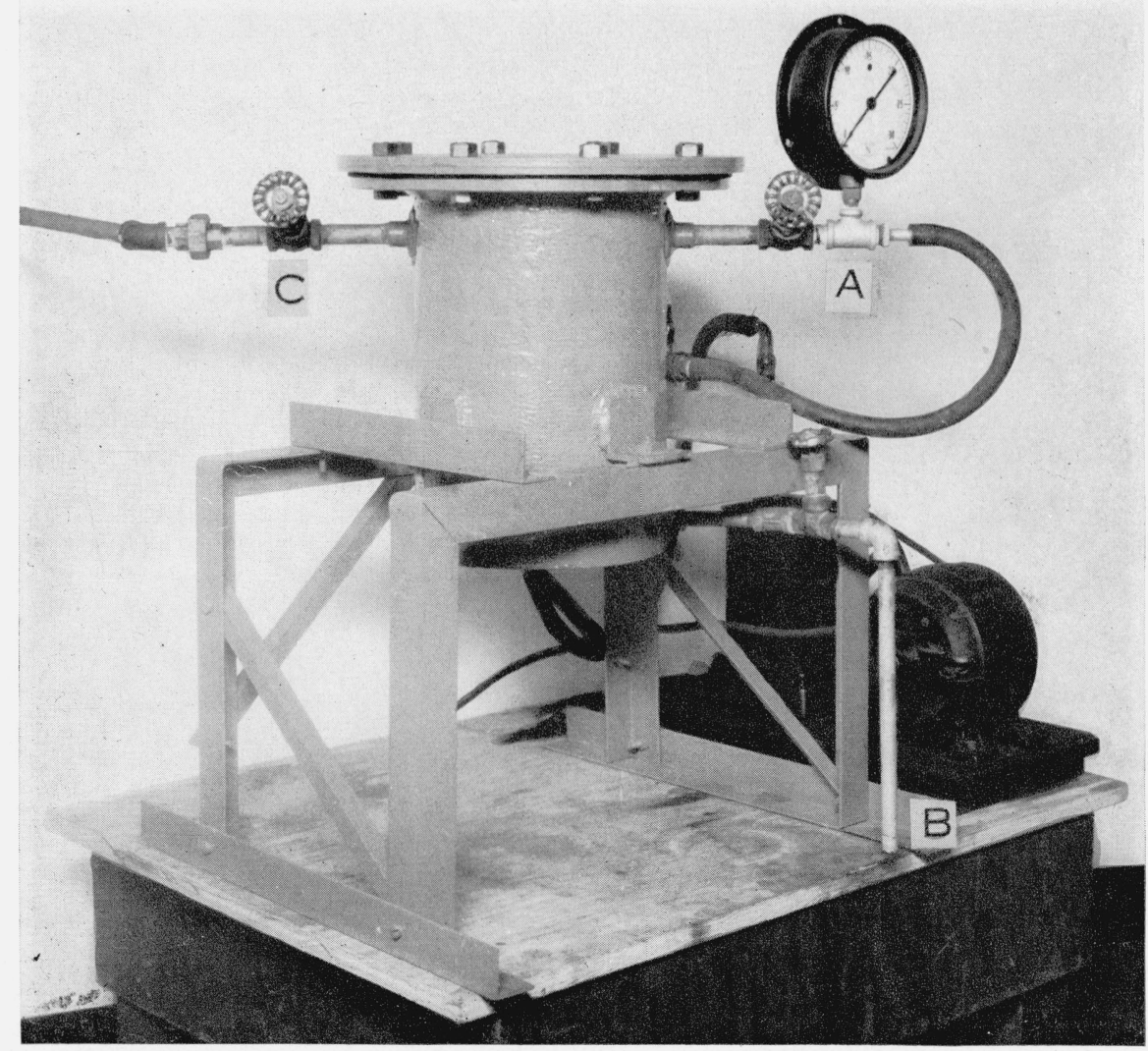

FIGURE 2.-Impregnating chamber used in sealing porous castings.

$A$, Vacuum gauge and connection to vacuum pump; $B$, inlet tube for admitting sealant; $C$, connection to supply of high-pressure air. 
at one end and provided with a flange at the top end. The top was closed with a $1 / 2$-inch steel cover plate fitted with a rubber gasket and held in place by bolts. Air and vacuum connections were welded into the side of the vessel near the top, and a connection for admitting the resin was located near the bottom. Each of these connections was controlled with a valve and a drainage hole in the bottom was closed with a pipe plug.

The impregnating chamber permitted treatment of 10 specimens at one time with about one-half gallon of resin. The 10 specimens used for each test were selected so that specimens of reasonably comparable porosity were treated with each resin. The procedure consisted in placing the cleaned and dried specimens in the chamber, closing all openings except the one to the vacuum pump, and evacuating to a vacuum of 28 or 29 inches of mercury for 1 hour. Then sufficient sealant was drawn in to cover the specimens and an air pressure of $75 \mathrm{lb} /$ in. $^{2}$ applied for 1 hour. After the pressure was released, the sealant was withdrawn and the specimens were allowed to drain. Most of the adhering resin was removed by wiping. A rinse in a suitable solvent, followed by wiping with a clean rag, removed the last of the sealant from the surfaces. The specimens were then cured under conditions recommended for each particular resin by the manufacturer. The curing schedules ranged from 1 hour at about $200^{\circ} \mathrm{F}$ to 4 hours at $275^{\circ}$ to $350^{\circ} \mathrm{F}$. In the case of many of the resins some exudation occurred during curing but the exuded material was removed before making pressure tests. The exudation that occurred during the curing of a porous aluminum specimen impregnated with a phenolic resin is shown in figure 3 .

Fourteen resins were selected for investigation, representing commercially available products. Six of these have been recommended specifically as sealants; the others were selected for comparison with the commercial sealants. A low viscosity is an important requisite for sealants to insure penetration, but it is questionable whether or not this property should be gained at the expense of the solids content of a resin through dilution with volatile solvents. For most of the resins the desired viscosities were obtained by using suitable amounts of the more fluid reactants like styrene in the copolymerizing resins; a few of the resins required dilution with solvents but these additions were not made on the basis of equal fluidities. One resin, No. 3, contained no added solvent and the viscosity of this sealant was somewhat higher than for the others.

\section{Results of Impregnation Tests}

The results of the sealing treatments with the various resins as indicated by pressure tests are shown in table 1 . In this and in subsequent

TABLE 1.-Results of sealing treatments with different resins as indicated by pressure tests a

\begin{tabular}{|c|c|c|c|c|}
\hline \multirow{2}{*}{ Type of resin } & \multirow{2}{*}{$\begin{array}{l}\text { Num- } \\
\text { ber of } \\
\text { porous } \\
\text { speci- } \\
\text { mens } \\
\text { treated }\end{array}$} & \multicolumn{2}{|c|}{$\begin{array}{l}\text { Percentage of } \\
\text { specimens } \\
\text { sealed in- }\end{array}$} & \multirow{2}{*}{ Remarks } \\
\hline & & $\begin{array}{l}1 \mathrm{im-} \\
\text { preg- } \\
\text { nation }\end{array}$ & $\begin{array}{c}2 \text { im- } \\
\text { preg- } \\
\text { nations }\end{array}$ & \\
\hline 1. Styrene-polyester b_-_- & 10 & 20 & 20 & \\
\hline 2. ... do $b_{\ldots}$ & 10 & 20 & & \\
\hline 3. Phenolic b & 13 & . 46 & 46 & $\begin{array}{l}\text { Resin has high solids } \\
\text { content. }\end{array}$ \\
\hline 4. Styrene-polyester ${ }^{\circ}$ & 12 & 33 & 66 & \\
\hline 5. Polyester ${ }^{\circ}$ & 10 & 50 & & \\
\hline $\begin{array}{l}\text { 6. Unsaturated polyes- } \\
\text { ter. }{ }^{\circ}\end{array}$ & 10 & 20 & 30 & \\
\hline 7. .... do c & 10 & 30 & $-\ldots$ & $\begin{array}{l}\text { Resin No. } 6 \text { with wet- } \\
\text { ting agent. }\end{array}$ \\
\hline
\end{tabular}

TABLE 1.-Results of sealing treatments with different resins as indicated by pressure tests ${ }^{a}$-Continued

\begin{tabular}{|c|c|c|c|c|}
\hline \multirow{2}{*}{ Type of resin } & \multirow{2}{*}{$\begin{array}{l}\text { Num- } \\
\text { ber of } \\
\text { porous } \\
\text { speci- } \\
\text { mens } \\
\text { treated }\end{array}$} & \multicolumn{2}{|c|}{$\begin{array}{l}\text { Perceniqge of } \\
\text { specimens } \\
\text { sealed in-. }\end{array}$} & \multirow{2}{*}{ Remarks } \\
\hline & & $\begin{array}{c}1 \mathrm{im-} \\
\text { preg- } \\
\text { nation }\end{array}$ & $\begin{array}{c}2 \text { im- } \\
\text { preg- } \\
\text { nations }\end{array}$ & \\
\hline 8. Styrene-alkyd ${ }^{\circ}$ & 10 & 30 & & \\
\hline $\begin{array}{l}\text { 9. Phenol-f or ma ld e - } \\
\text { hyde.c }\end{array}$ & 10 & 30 & & $\begin{array}{l}\text { Low molecula veight } \\
\text { resin. }\end{array}$ \\
\hline $\begin{array}{l}\text { 10. Resorcinal - formalde- } \\
\text { hyde. }{ }^{\circ}\end{array}$ & 9 & 11 & & Fast-curing resin. \\
\hline 11. Styrene-alkyd o & 10 & 20 & & \\
\hline $\begin{array}{l}\text { 12. Phenolic with silice- } \\
\text { ous filler.b }\end{array}$ & 10 & 10 & & $\begin{array}{l}\text { Resin contains } 65 \% \\
\text { solids. }\end{array}$ \\
\hline 13. Phenolic b & 38 & 58 & 79 & $\begin{array}{l}\text { Resin contains } 52 \% \\
\text { solids. }\end{array}$ \\
\hline 14. Styrene-polyester d... & 36 & 47 & 86 & \\
\hline
\end{tabular}

a Specimens were tested at a hydrostatic pressure of $600 \mathrm{lb} / \mathrm{in} .{ }^{2}$ for 5 minutes.

b Recommended by the manufacturer for general use.

- Resins not marketed as sealants.

d Recommended by the manufacturer for aluminum or magnesium alloys. 
tables, the sealants are arranged according to arbitrarily assigned numbers with the type of resin indicated. For some of the resins, data are given to show the effect of a second treatment on the specimens that had not been completely sealed in the initial treatment. Only four of the resins successfully sealed 46 percent or more of the specimens in one treatment. One of these, No. 3, showed a sealing efficiency of 46 percent in the initial treatment but indicated no improvement in the second treatment. Resin No. 5 sealed 50 percent of the test specimens in one treatment, but the curing of this resin was catalysed by contact with copper even at room temperature and the bronze specimens became coated with a solid material during impregnation, which was exceed- ingly difficult to remove. Two of the sealants, No. 13 and No. 14, made the best showing. No. 13 is a phenolic resin in alcohol solution and is recommended by the manufacturer for eliminating leakage in all types of metals and alloys. No. 14 is a styrene-polyester resin developed particularly for sealing aluminum and magnesium castings. In the initial treatment No. 13 sealed 58 percent of the specimens tested and No. 14 sealed 47 percent. After two treatments the total percentages sealed were 79 percent and 86 percent, respectively, for the two resins.

As these two resins were the only ones that yielded reasonably satisfactory results in the sealing treatments, durability tests were confined to specimens repaired with these sealants.

\section{Durability Tests on Sealed Specimens}

Repaired castings must withstand exposure to service conditions in addition to being pressure tight immediately after the impregnation treatment. Thus it is important to know how the sealing material will withstand exposure to hot motor oil, high octane gasoline, or boiling water over extended periods. Likewise a knowledge of the effect of elevated temperatures or of hydraulic pressures in excess of $600 \mathrm{lb} / \mathrm{in.}^{2}$ may be of importance in some applications. Another factor deserving consideration is the ability of the sealed casting to withstand thermal shock.

In order to evaluate the durability of the seal produced by the two most efficient sealants, a number of experiments were conducted. In most of these tests five specimens sealed with each resin were exposed simultaneously under each condition, and the durability was judged by pressure tests on the specimens, either at regular intervals or upon completion of the exposure test.

\section{Exposure to liquids}

The effects of exposure to motor oil at $250^{\circ} \mathrm{F}$, high octane gasoline (AN-F-28 fighter fuel) at room temperature, and boiling water were determined by completely immersing sealed specimens in each medium. The exposure tests were continued for 16 weeks, the specimens being removed for pressure tests at intervals of 4 weeks. Sound specimens were replaced for further exposure after each pressure test. The results of these tests are given in table 2 .

TABLE 2.-Results of the exposure of sealed specimens in liquids

\begin{tabular}{|c|c|c|c|c|c|c|}
\hline \multirow{2}{*}{ Sealant } & \multirow{2}{*}{ Exposure medium } & \multirow{2}{*}{$\begin{array}{l}\text { Number } \\
\text { of spec- } \\
\text { imens } \\
\text { tested }\end{array}$} & \multicolumn{4}{|c|}{$\begin{array}{l}\text { Number of specimens pres- } \\
\text { sure tight } \text { after- }\end{array}$} \\
\hline & & & $\begin{array}{c}4 \\
\text { weeks }\end{array}$ & $\begin{array}{c}8 \\
\text { weeks }\end{array}$ & $\begin{array}{c}12 \\
\text { weeks }\end{array}$ & $\begin{array}{c}16 \\
\text { weeks }\end{array}$ \\
\hline No. $13_{-}$ & Motor oil at $250^{\circ} \mathrm{F}$ & 5 & 4 & 2 & 2 & 2 \\
\hline No. 14. & - do & 5 & 5 & 4 & 4 & 4 \\
\hline No. 13 - & $\begin{array}{l}\text { High-octane gasoline at } \\
\text { room temperature. }\end{array}$ & 5 & 3 & 2 & 2 & 2 \\
\hline No. 14 & c do & 5 & 5 & 5 & 5 & 5 \\
\hline No. 13 & Boiling water.... & 5 & 5 & 4 & 4 & 4 \\
\hline No. 14 & ..... do & 5 & 4 & 4 & 4 & 4 \\
\hline
\end{tabular}

a Pressure tested at $600 \mathrm{lb} / \mathrm{in} .{ }^{2}$ for 5 minutes.

\section{Effect of elevated temperatures}

The stability of the two sealants at elevated temperatures was determined by exposing sealed specimens in air at a specified temperature for 5 hours, pressure testing the specimens, and then exposing the pressure tight specimens at a higher temperature. This procedure was continued until all of the specimens had failed. The first exposure was at $400^{\circ} \mathrm{F}$ and the temperature was increased by $100^{\circ} \mathrm{F}$ in each successive cycle. The results of the tests are given in table 3 . 
TABLE 3.-Results of exposure of sealed specimens at elevated temperatures

\begin{tabular}{l|r|r|r|r|r}
\hline \hline \multirow{2}{*}{ Sealant } & \multirow{2}{*}{$\begin{array}{c}\text { Number } \\
\text { of speci- } \\
\text { mens } \\
\text { tested }\end{array}$} & \multicolumn{3}{|c}{$\begin{array}{r}\text { Number of specimens pressure tight a } \\
\text { after 5 hours at - }\end{array}$} \\
\cline { 3 - 7 } & & $400^{\circ} \mathrm{F}$ & $500^{\circ} \mathrm{F}$ & $600^{\circ} \mathrm{F}$ & $700^{\circ} \mathrm{F}$ \\
\hline No. 13 & 5 & 4 & 4 & 1 & 0 \\
No. 14 & 5 & 3 & 1 & 0 & $\ldots$ \\
\hline
\end{tabular}

- Pressure tested at $600 \mathrm{lb} / \mathrm{in} .^{2}$ for 5 minutes.

\section{Effect of testing at pressures in excess of $600 \mathrm{lb} /$ in. $^{2}$}

Another group of castings was tested to determine the maximum pressures that the sealed specimens could withstand. The specimens were first subjected to a hydrostatic pressure of $700 \mathrm{lb} / \mathrm{in} .^{2}$ for 5 minutes. Those specimens which were sound at this pressure were then tested at $800 \mathrm{lb} / \mathrm{in}^{2}$. The pressures were thus increased by increments of 100 to $200 \mathrm{lb} / \mathrm{in}^{2}$ until leaks developed in all of the specimens. The results of these tests are shown in table 4.

\section{Effect of thermal shock and aging}

The ability of the sealed castings to withstand thermal shock was determined by alternately
TABLE 4.-Results of tests on sealed specimens at pressures higher than $600 \mathrm{lb} /$ in. $^{2}$

\begin{tabular}{|c|c|c|c|c|c|}
\hline \multirow{2}{*}{ Sealant } & \multirow{2}{*}{$\begin{array}{c}\text { Number } \\
\text { of } \\
\text { speci- } \\
\text { mens } \\
\text { tested }\end{array}$} & \multicolumn{4}{|c|}{$\begin{array}{l}\text { Number of specimens pressure tight } \\
\text { after } 5 \text { minutes at- }\end{array}$} \\
\hline & & $\begin{array}{c}700 \\
\mathrm{lb} / \mathrm{in} .{ }^{2}\end{array}$ & $\begin{array}{c}800 \\
\text { lb/in. }{ }^{2}\end{array}$ & $\begin{array}{c}1,000 \\
1 b / i n .\end{array}$ & $\begin{array}{c}1,200 \\
\mathrm{lb} / \mathrm{in} .{ }^{2}\end{array}$ \\
\hline No. 13... & 3 & 3 & 1 & 1 & 0 \\
\hline No. 14 & 4 & 3 & 0 & & \\
\hline
\end{tabular}

immersing the specimens in baths at $212^{\circ}$ and $32^{\circ} \mathrm{F}$, respectively. The castings were kept in each bath until they attained the temperature of the medium. After 25 cycles (50 changes of temperature) the specimens were tested for pressure tightness. Four of the five specimens treated with resin No. 13 had developed leaks, whereas only one of the five specimens sealed with resin No. 14 had failed.

Five specimens sealed with each resin were retested for pressure tightness after storage at room temperature for 6 months. No change had occurred in any of the specimens during this period.

\section{Discussion of Results and Conclusions}

Of fourteen resins tested to determine their efficiency as sealants for porous castings, only two showed promise in this respect. Even these two resins sealed only 50 percent of the specimens subjected to one treatment but a second impregnation increased the sealing efficiency to about 80 percent. As a double treatment does not insure complete sealing, it is necessary to test all castings to identify those which have not been sealed. This undesirable feature necessarily limits the value of the process, and for that reason the use of sealants, except in some special applications, probably will be resorted to only in emergencies.

Regardless of the circumstances requiring the use of a given sealant, its durability under service conditions should be given first consideration. The results of the tests indicated that a resin may be decidedly superior for one type of exposure but may be of questionable value under other service conditions. Thus the styrene-polyester resin (No. 14) was considerably more satisfactory than the phenolic resin (No. 13) in exposure to petroleum products (table 2), while the phenolic resin was superior for elevated temperature conditions. In addition, the phenolic resin required the application of higher pressures to produce failure at room temperatures. Both resins were reasonably stable in exposure to boiling water. Under thermal shock conditions the polyester resin (No. 14) was. decidedly superior. Undoubtedly this is due to the fact that the latter forms a resilient material upon curing whereas the phenol-formaldehyde resin is converted into a glassy, brittle mass that fractures readily as the casting expands and contracts. 
Although impregnation with sealants now available may be a useful method for rendering certain types of porous castings pressure tight for limited service conditions, the results of this investigation suggest that in general the production of leakproof castings remains essentially a foundry problem. Thus the development of pressuretightness in castings, in general, will result from careful design, judicious selection of alloys, and the application of good foundry practice. It is better to avoid the formation of porosity than to try to remedy it.

\section{References}

[1] Sealing porous castings, Light Metals 1, 185 (1938).

[2] Repair of porous castings (a composite abstract), Metals \& Alloys 19, 920 (1944).

[3] Wants to repair leaky castings, Foundry $\boldsymbol{g 1}, 122$ (Oct. 1943).

[4] Plastic treatment for porous castings, Engineer 1\%5, 293 (1943).

[5] P. S. Fuller, Sealing porous castings, Materials and Methods 22, 1746 (1945).

[6] Verschiedene Verfahren zum Beseitigen von undichten Stellen an Formguss und anderen Werkstücken Die Giesserie 23, 386 (1936).
[7] W. M. Corse, Reclaiming leaky castings, Metals \& Alloys 3, 255 (1932).

[8] S. H. Brahms, Magnesium castings impregnated by new method, Iron Age 152, 57 (Nov. 11, 1943).

[9] Styrene DMI for impregnation of non-ferrous castings (Bulletin), Dow Chemical Co., Midland, Mich.

[10] R. W. Crawford and S. E. Glick, Sealants for metal castings for varying degrees of porosity, Product Eng. 16, 53 (1945).

[11] H. A. Knight, Modern impregnating of magnesium castings, Metals \& Alloys 20, 1625 (1944).

Washington, May 29, 1946. 